\title{
Trichomoniasis- An Overlooked Sexually Transmitted Disease
}

\author{
Authors \\ Dr Poonam Woike, Dr Rajesh Gaur, Dr Rajlaxmi Sharma, Dr Yashodhara Gaur \\ Department of Pathology, G.R Medical College \& J.A Hospital Gwalior, India \\ Corresponding Author \\ Dr Poonam Woike \\ \#35, Senior Girls Hostel, J.A Hospital Campus, Lashkar, Gwalior,M.P, India \\ Email:poonam.woike@gmail.com, Telephoneno- 7745983670
}

\begin{abstract}
Background- Trichomoniasis is a sexually transmitted disease of worldwide importance. Women infected during pregnancy are predisposed to premature labor, low birth weight infants and may amplify HIV transmission. Cervicovaginal smear examination is now considered an effective technique for early diagnosis of Trichomonasis.

Aims and Objectives- To study the prevalence of Trichomonasis in Gwalior, role of cervicovaginal smear examination in it's diagnosis and spectrum of disease in various age groups.

Methodology- This is a retrospective study. Cases reported over the period of 5 years, from January 2010December 2014 are included in the study. Sample size was greater than 20000 cases and age group was between 20-70 years. The data of cervicovaginal smear examination reported in past five years were retrieved, compiled and analyzed.

Results and Conclusions- Out of 24,292 cases reported, 372 (1.53\%) females were positive for Trichomoniasis, with highest incidence found in women aged between 30-39 years (47.31\%). Cervicovaginal smear examination with Leishman-Giemsa staining would help in early detection of Trichomoniasis which can prevent various complications in women chiefly in the reproductive age group.

Key Words- Trichomoniasis, Premature, HIV, Leishman-Giemsa, Cervicovaginal Smear
\end{abstract}

\section{Introduction}

Trichomonas vaginalis is a parasitic protozoan that is the cause of Trichomoniasis, a sexually transmitted disease (STD) of worldwide importance. Although the disease was first described as a clinical entity by Hohne in $1916,{ }^{[1]}$ the etiological agent, T. vaginalis was first identified by Donne' who visualized motile microorganisms in the purulent, frothy leukorrhea of women presenting with vaginal discharge and genital irritation. ${ }^{[2]}$ In the 1960s and 1970s, the research focused on biochemical tests and microscopic examination to understand the growth characteristics and behavior of the organism.

The classic acute signs and symptoms include purulent yellowish-green, often frothy, malodorous, thin discharge with burning, itching at the site; dysuria and dyspareunia. The vulva may appear fiery red and oedematous. The speculum examination often reveals mucosal 
erythema and punctuate haemorrhage, the so called "strawberry" vagina and cervix.

The actual burden of the disease remains unknown. As per the published literature, the worldwide prevalence of $\mathrm{T}$. vaginalis ranges from $0.4-27.4 \%$ in women and $0.0-5.6 \%$ in $\operatorname{men}^{[3]}$. Trichomonas vaginitis is one of the most common STDs among HIV-infected and un-infected women. Proportion of HIV-infected women diagnosed with T.vaginalis vaginitis ranges from 6 to $27 \%^{[4]}$.

It has been seen that women infected during pregnancy are predisposed to premature labor and low birth weight infants ${ }^{[5-6]}$. Further, it may amplify HIV transmission ${ }^{[7-8]}$, but prevention of Trichomoniasis has not been a priority due to lack of understanding of its public health implication and lack of resources. Therefore, there is a need for increased screening and treatment of this easily curable sexually transmissible infection in India.

The present study describes the burden and correlation of $\mathrm{T}$. vaginalis infection among women and use of cervicaovaginal smear examination by Leishman-Giemsa staining for its diagnosis in our region.

\section{Materials and Methods}

Patients visiting the Gynaecology OPD with complaints of vaginal discharge, itching, dysuria, dyspareunia, and foul odour between the age group 20-70 years were considered symptomatic. Informed consent was taken from them and Cervicovaginal smear from each patient was carefully taken with aseptic precautions from January 2010- December 2014 (5 years) and prepared slides were sent for examination in the Department of Pathology, Cytopathology Section. The smear was air dried and was covered by Leishman stain for one minute, 2 drops of Giemsa stain was also added. After 10 seconds, it was diluted with distilled water and kept for 10 minutes. Then washed in running water, dried in air and mounted with Dibutyl Phathalate Xylene (D.P.X) mountant media. Total sample size was 24,292 cases. The slides were examined and reported by experienced cytologists and records were maintained in the master register. The data from the 2010-2014 were retrieved, compiled, summarized and statistically analyzed by frequency distribution and percentage proportion.

Limitations of the study- the study could only be carried out in the patients who visited the OPD of our centre so the actual prevalence in this region was not ruled out due to the undiagnosed hidden cases in this region.

\section{Results}

A total number of 24,292 cases were reported through cervicovaginal smear examination from January 2010- December 2014 out of which 372 (1.53\%) cases were positive for trichomonas infection. The number of cases positive in individual year is shown in Table no. 1 .

The positive cases were further divided into various age groups which showed that out of 372 positive cases $69(18.54 \%)$ patients were in their 20 's, $176(47.31 \%)$ were in their 30's, 96 $(25.38 \%)$ in 40 's, $22(5.91 \%)$ in 50's and 9 ( $2.41 \%$ ) were in their 60 's (table no.2, fig. no.1). Approximately $50 \%$ of cases which were positive for Trichomoniasis presented between the month of October to February, which showed a heavy burden of the infection in the winter season. 


\section{JMSCR Vol||3||Issue ||10||Page 7817-7822||October}

Table No. 1-Year wise distribution of Cases of Trichomoniasis

\begin{tabular}{|l|l|l|l|}
\hline Year & Number Of Cases & Positive & Percentage \\
\hline 2010 & 3605 & 83 & $2.30 \%$ \\
\hline 2011 & 3808 & 74 & $1.94 \%$ \\
\hline 2012 & 4675 & 72 & $1.54 \%$ \\
\hline 2013 & 5600 & 71 & $1.26 \%$ \\
\hline 2014 & 6604 & 72 & $1.09 \%$ \\
\hline
\end{tabular}

Table No. 2 -Age Wise Distribution Of The Cases Positive For Trichomoniasis

\begin{tabular}{|l|c|c|}
\hline Age Group (In Years) & Number Of Cases & Percentage \\
\hline $20-29$ & 69 & $18.54 \%$ \\
\hline $30-39$ & 176 & $47.31 \%$ \\
\hline $40-49$ & 96 & $25.38 \%$ \\
\hline $50-59$ & 22 & $5.91 \%$ \\
\hline $60-69$ & 09 & $2.41 \%$ \\
\hline
\end{tabular}

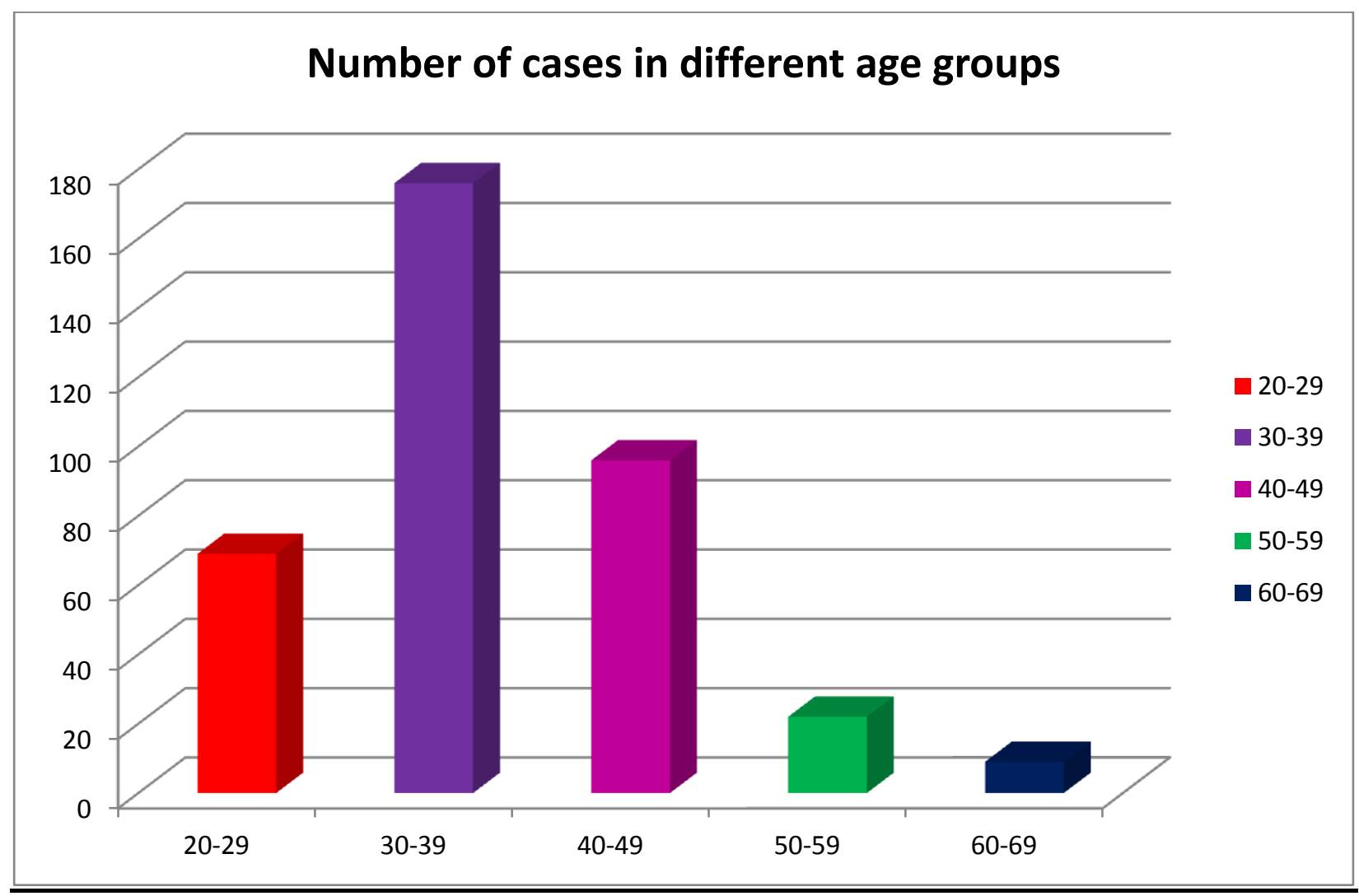

Fig no. 1 : Distribution of positive cases of trichomoniasis in different age groups 


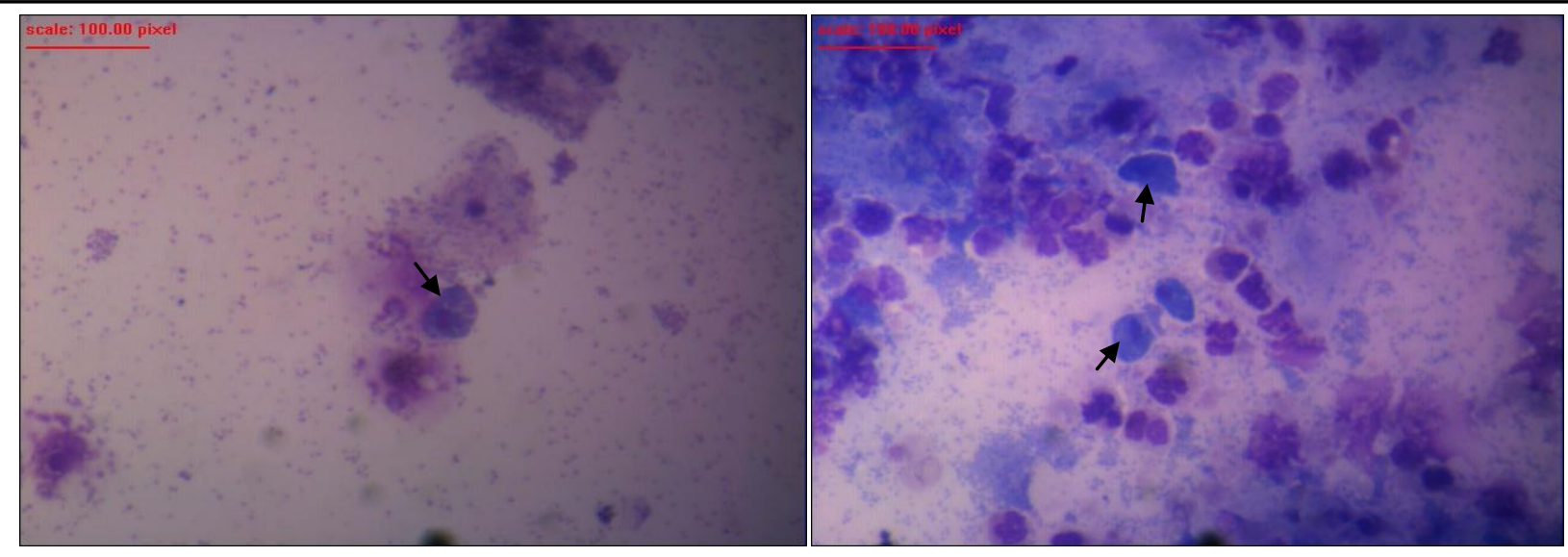

Figure Showing Single Trichomonas MGG , 40X

Figure Showing Multiple Trichomonas
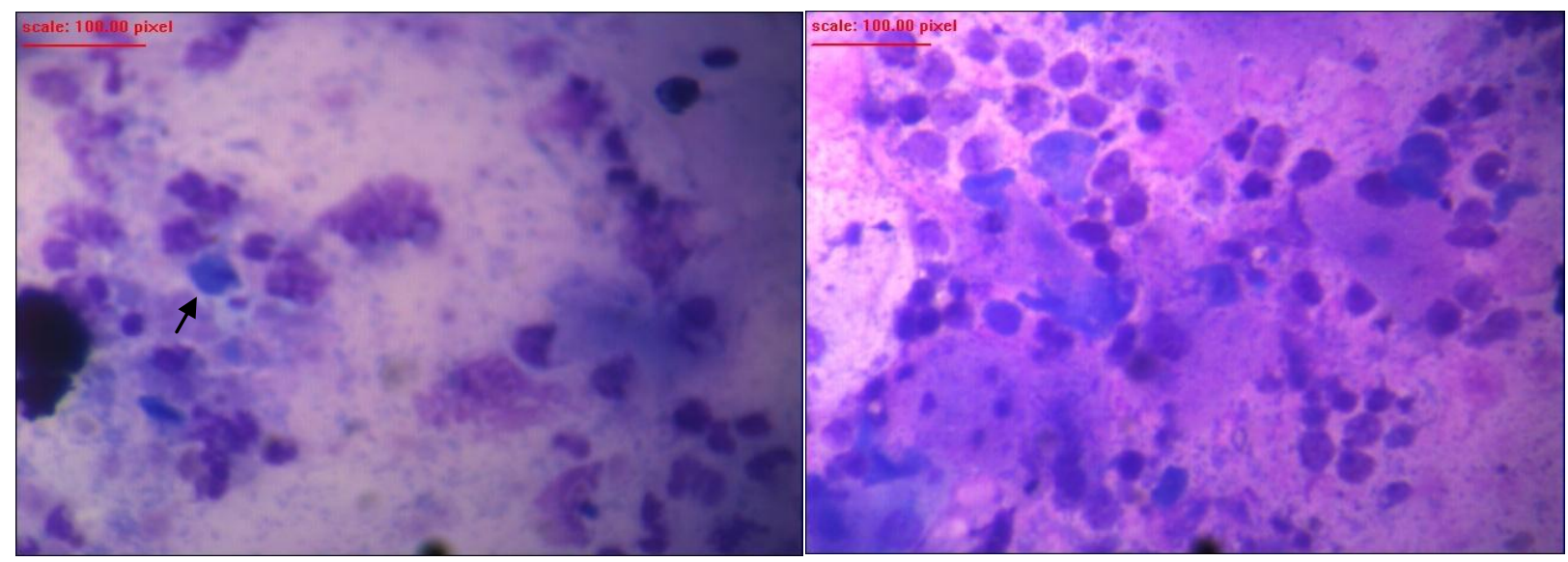

Figures Showing Muliple Trichomonas With Acute Infection

\section{Discussion}

Trichomoniasis is a sexually transmitted infection (STI) caused by a parasite. It can affect women or men. Many people who have the infection have no symptoms, but when symptoms occur, they include vaginal or urethral (in men) discharge that may appear greenish and frothy, burning on urination, discomfort during sex, and itching in the genital area. Diagnosis is based upon identifying the parasite through miscroscopic examination in the vaginal or urethral discharge, they appear to be pear shaped, oval to round cyanophilic flagellate organism size varying from 15-30 micron, nucleus is pale, vesicular and eccentrically located and they sometimes attach to the surface of squamous cells to form a ring around the margin. Trichomoniasis is the most common curable $\underline{\text { STD }}$ in young, sexually active women. An estimated 7.4 million new cases occur each year in women and men. In pregnant women it may cause premature rupture of the membranes that protect the baby and early delivery. Trichomoniasis is associated with increased risk of transmission and infection of HIV ${ }^{[9]}$.In the present study a cervicovaginal smear with Leishman- Giemsa staining is used for its diagnosis. A total number of 24,292 cases were examined through cervical smear using LeishmanGiemsa staining method from January 2010December 2014 with 372 females positive for trichomonas infection $(1.53 \%)$. The results reveal that from the year 2010 to 2014 there is a radical increase in the number of patients who went through a cervicovaginal smear examination. In 2010 there were 3605 cases which increased upto 6604 cases in 2014. This represents that in the past years the awareness of people regarding genital tract infection is improved. It can also be concluded that with proper diagnosis, medical intervention and treatment there is decline in the 
prevalence of cases from 2010-2014 i.e. from $2.30 \%$ to $1.09 \%$. The above data also shows that the highest incidence of Trichomonas infection in Gwalior was found in the women aged between 30 -39 years $(47.31 \%)$, followed by women in 40 's (25.8\%), 20's (18.54\%), 50's (5.91\%) respectively and least in the 60's (2.41\%). There is also a noticeable seasonal variation in the number of cases positive for Trichomonas infection, most of them presented between the month of OctoberFebruary and maximally in people living in rural area (lower socioeconomic group) which shows that it's more common in winter season and in people living in poor hygienic and poor sanitary conditions.

A study done by Madhivanan P et al showed the burden of $\mathrm{T}$. vaginalis infection $8.5 \%$, relatively high among a community sample of young reproductive aged women ${ }^{[10]}$.Another study done by SR Fule et $\mathrm{al}^{[11]}$ showed that out of the 156 women examined with vaginal discharge, 19 (12.06 \%) showed $T$. vaginalis infection. The prevalence rate of $1.53 \%$ found in this study is significantly lower than $12.3 \%$ found in Abakiliki, Southern Nigeria [26] ,4.7\% in Ilorin, [27] 5.2\% in Calabar [19] and $2.8 \%$ in another study from South Eastern Nigeria.[6] Other researchers found much higher prevalence. These include $17.7 \%$ in Uyo Nigeria ${ }^{[12]}, 18.66 \%$ in Zaria Nigeria ${ }^{[13]}$, $24.1 \%$ in Jos Nigeria ${ }^{[14]}, 46.9 \%$ in New York ${ }^{[15]}$ and $36.1 \%$ in Nebraska ${ }^{[16]}$ These differences in prevalence could be explained on the basis of differences on social, cultural and environmental factors. All the women affected by trichomoniasis belonged to active reproductive age group, i.e. 2040 years. In our study the most common age group was $30-39 \%(47.31 \%)$ a similar study showed T.vaginalis infection prevalence was highest in women aged $39-44$ years $(21.1 \%) .{ }^{[17]}$

\section{Conclusion}

Trichomoniasis is found worldwide. With early diagnosis and proper treatment, the outcome is likely to be excellent. It can be seen from the above data that cervicovaginal smear examination with Leishman-Giemsa staining would equally help in early detection and treatment of Trichomoniasis like pap smear examination which can prevent various complications like premature rupture of membrane, low birth weight infants and HIV transmission in women chiefly in the reproductive age group. Proper medical intervention, diagnosis and treatment showed decline in the prevalence of Trichomoniasis. Also, in the past five years the awareness of people regarding Sexually Transmitted Diseases is increased which is seen by the raise in number of patients who went through a cervicovaginal smear examination. The highest incidence in Gwalior was found in the women aged between 30-39 years $(47.31 \%)$ which was more common in winter season and highest in people living in poor hygienic conditions.

\section{References}

1. Hohne O. Trichomonas vaginalis als haufiger erreger ciner typischen colpitis purulenta. Centralblatt Gynaekol 1916;40:4-15.

2. Donne A. Animalcules observes dans les matieres purulentes et le produit des secretions des organs genitaux de I'homme et de la femme. CR Behd. Seances Acad Sci 1836;3:385-6.

3. Hawks S. Santya KG. Diverse realities : Sexually transmitted infections and HIV in India. Sex Transm Infect 2002:78 (Suppl. 1) :i31-9.

4. Cohn SE, Clark RA. Sexually transmitted diseases: HIV AIDS in women. Med Clin North Am 2003;87:971-9

5. Hardy PH, Hardy JB, Nell EE, Graham DA, Spence MR,Rosenbaum RC. Prevalence of six sexually transmitted disease agents among pregnant inter-city adolescents and pregnancy outcome. Lancet 1984:ii:333-7.

6. Cotch MF. Carriage of Trichomonas vaginalis (Tv) is associated with adverse pregnancy outcome. In program and abstracts of the $30^{\text {th }}$ Interscience Conference on Anti microbial agents and 
Chemotherapy. Washington, DC:

American Society for Microbiology: 1990.p. 199.

7. Cameron DW, Padian NS. Sexual transmission of HIV and the epidemiology of other sexually transmitted diseases. AIDS 1990:4:599-103.

8. Laga M.Nzila N. Goeman J. The interrelationship of sexually transmitted diseases and HIV infection :Implications for the control of both epidemics in Africa. AIDS 1991:5(Suppl.1):555:63.

9. Secor W, Meites E, Starr M, Workowski K. Neglected parasitic infections in the United States: trichomoniasis. Am J Trop Med Hyg. 2014;90(5):800-804. doi:10.4269/ajtmh.13-0723.

10. Madhivanan P, Bartman MT, Pasutti L, Krupp K, Arun A, Reingold AL, Klausner JD. Prevalence of Trichomonas vaginalis infection among young reproductive age women in India: implications for treatment and prevention. 2009 Dec;6(4):339-44. doi: 10.1071/SH09038.

11. SR Fule, RP Fule, NS Tankhiwale Clinical and laboratory evidence of Trichomonas vaginalis infection among women of reproductive age in rural area Indian Journal of Medical Microbiology, Vol. 30, No. 3, July-September, 2012, pp. 314-316.

12. Opara K, Udoidiung N, Atting I, Bassey E, Okon E, Nwabueze A : Risk Factors For Vaginal Trichomoniasis Among Women In Uyo, Nigeria. The Internet Journal of Health.. 2009 ;9 (2): 101-115.

13. Jatau, ED, Olonitola SA and Olayinka AT. Prevalence of Trichomonas Infection Among Women Attending Antenatal Clinics in Zaria, Nigeria. Annals of African Medicine, 2006; 5(4): 178-181.

14. Jombo GTA, Egah DZ. Banwate EB, Opajobi $S$ O. High vaginal and endocervical swabs: A bacteriological study of 8,433 samples in Jos, Nigeria.
Journsal of Medical Laboratory Science. 2006; 15: (2): 41-46.

15. Shuter J, Bell D, Graham D, Holbrook KA, Bellin EY. Rates of and risk factors for trichomoniasis among pregnant inmates in New York City. Sex Transm Dis 1998; 25: 303-7. (s)

16. Franklin TL, Monif GR. Trichomonas vaginalis and bacterial vaginosis. Coexistence in vaginal wet mount preparations from pregnant women. J Reprod Med 2000; 45:131-4.

17. A G Mairiga , H J Balla, M I Ahmad Prevalence of trichomonas vaginalis infections among antenatal clients in Maiduguri Nigeria Int J Biol Med Res. 2011; 2(4): 998 - 1002. 